\title{
Fluorine-19 MRI at 21.1 T: enhanced spin-lattice relaxation of perfluoro-15-crown-5-ether and sensitivity as demonstrated in ex vivo murine neuroinflammation
}

\author{
Sonia Waiczies ${ }^{1}$ (1) . Jens T. Rosenberg ${ }^{2} \cdot$ Andre Kuehne $^{3} \cdot$ Ludger Starke $^{1} \cdot$ Paula Ramos Delgado ${ }^{1}$. \\ Jason M. Millward ${ }^{1}$. Christian Prinz ${ }^{1}$. Joao dos Santos Periquito ${ }^{1}$. Andreas Pohlmann ${ }^{1} \cdot$ Helmar Waiczies $^{3}$. \\ Thoralf Niendorf ${ }^{1,3,4}$
}

Received: 4 July 2018 / Revised: 16 October 2018 / Accepted: 18 October 2018 / Published online: 12 November 2018

(c) The Author(s) 2018

\begin{abstract}
Objective Fluorine MR would benefit greatly from enhancements in signal-to-noise ratio (SNR). This study examines the sensitivity gain of ${ }^{19} \mathrm{~F}$ MR that can be practically achieved when moving from 9.4 to $21.1 \mathrm{~T}$.

Materials and methods We studied perfluoro-15-crown-5-ether (PFCE) at both field strengths ( $\mathrm{B}_{0}$ ), as a pure compound, in the form of nanoparticles (NP) as employed to study inflammation in vivo, as well as in inflamed tissue. Brains, lymph nodes (LNs) and spleens were obtained from mice with experimental autoimmune encephalomyelitis (EAE) that had been administered PFCE NPs. All samples were measured at both $\mathrm{B}_{0}$ with $2 \mathrm{D}-\mathrm{RARE}$ and $2 \mathrm{D}-\mathrm{FLASH}$ using ${ }^{19} \mathrm{~F}$ volume radiofrequency resonators together. $T_{1}$ and $T_{2}$ of PFCE were measured at both $\mathrm{B}_{0}$ strengths.

Results Compared to 9.4 T, an SNR gain of $>3$ was observed for pure PFCE and $>2$ for PFCE NPs at $21.1 \mathrm{~T}$ using 2D-FLASH. A dependency of ${ }^{19} \mathrm{~F} T_{1}$ and $T_{2}$ relaxation on $\mathrm{B}_{0}$ was demonstrated. High spatially resolved ${ }^{19} \mathrm{~F}$ MRI of EAE brains and LNs at 21.1 $\mathrm{T}$ revealed signals not seen at $9.4 \mathrm{~T}$.

Discussion Enhanced SNR and $T_{1}$ shortening indicate the potential benefit of in vivo ${ }^{19} \mathrm{~F}$ MR at higher $\mathrm{B}_{0}$ to study inflammatory processes with greater detail.
\end{abstract}

Keywords Fluorine-19 magnetic resonance imaging · Magnetic fields · Experimental autoimmune encephalomyelitis · Signal-to-noise ratio

Electronic supplementary material The online version of this article (https://doi.org/10.1007/s10334-018-0710-z) contains supplementary material, which is available to authorized users.

Sonia Waiczies

sonia.waiczies@mdc-berlin.de

1 Experimental Ultrahigh Field MRI, Berlin Ultrahigh Field Facility (B.U.F.F.), Max Delbrück Center for Molecular Medicine in the Helmholtz Association, Robert-Roessle-Str. 10, 13125 Berlin, Germany

2 The National High Magnetic Field Laboratory, Florida State University, Tallahassee, FL, USA

3 MRI TOOLS GmbH, Berlin, Germany

4 Experimental and Clinical Research Center, A Joint Cooperation Between the Charite Medical Faculty and the Max Delbrück Center for Molecular Medicine in the Helmholtz Association, Berlin, Germany

\section{Introduction}

Fluorine-19 $\left({ }^{19} \mathrm{~F}\right)$ magnetic resonance (MR) methods have found their application in a wide range of biomedical research areas. One branch of research is the tracking of cells, including inflammatory cells, in vivo with the help of fluorine ${ }^{19} \mathrm{~F}$ nanoparticles (NPs) [1-7]. ${ }^{19} \mathrm{~F}$ MR methods provide several advantages over methods employing contrast agents such as iron oxide particles that modulate proton relaxation $[8,9]$. Iron oxide particles such as ultrasmall iron oxide agents are potentially advantageous with regard to their MR sensitivity, but suffer from drawbacks such as signal quantification and a difficulty to distinguish the contrast which they create in the cells they label from other intrinsic tissue contrasts [8]. Due to the absence of organic ${ }^{19} \mathrm{~F}$ in living organisms, the acquired ${ }^{19} \mathrm{~F}$ MR images are free from background signal, such that ${ }^{19} \mathrm{~F} /{ }^{1} \mathrm{H}$ MRI is able to localize labeled cells in vivo with complete signal 
selectivity and specificity. ${ }^{19} \mathrm{~F}$ MR directly detects the ${ }^{19} \mathrm{~F}$ spins in the cells labeled with ${ }^{19} \mathrm{~F}$ NPs, meaning that ${ }^{19} \mathrm{~F}$ NPs are cell labels, rather than contrast agents. The possibility of quantifying inflammatory cells by ${ }^{19} \mathrm{~F}$ MR spectroscopy is another advantage, allowing a quantitative assessment of inflammation and of anti-inflammatory strategies. However, the usefulness of ${ }^{19} \mathrm{~F}$ MR in a wide range of biomedical imaging applications is hampered by the low availability of ${ }^{19} \mathrm{~F}$ spins in the living organism. This is compounded by the fact that the signal sensitivity of current state-of-the-art MR equipment remains limited, making ${ }^{19} \mathrm{~F}$ MR measurements of fluorine compounds present at low concentrations an extremely challenging task.

Therefore, there is a need to improve the sensitivity of the measuring instrument to increase the signal-to-noise ratio (SNR). One way to improve signal sensitivity is to increase the strength of the static magnetic field $\left(\mathrm{B}_{0}\right)$ [10], a strategy which has also been actively pursued for clinical application [11]. Intrinsic SNR is expected to grow at least linearly with increasing frequency and $\mathrm{B}_{0}$ strengths [12-14]. In early seminal studies using solenoid RF coils at frequencies $(f)$ below $1 \mathrm{MHz}$, the maximum sensitivity was expected to be proportional to the frequency: sensitivity $\propto f^{1.75}$; this proportionality approached linearity when sample losses predominated $[12,13]$. At low field strengths, the principle of reciprocity can be used to calculate the receive field $\left(B_{1}\right)$ sensitivity of a single channel RF coil in terms of the transmit field $\left(\mathrm{B}_{1}{ }^{+}\right)$ that can be easily measured [15]. In the high-field domain, the increasing $f$ and the influence of wave propagation need to be considered [10]. The homogeneity of the $\mathrm{B}_{1}{ }^{+}$field is expected to decline with increasing $\mathrm{B}_{0}$, thereby influencing the overall SNR gain. An experimental study investigating SNR dependency on $\mathrm{B}_{0}$ in the human brain revealed SNR $\propto \mathrm{B}_{0}^{1.65}$ in the range of $3.0 \mathrm{~T}$ to $9.4 \mathrm{~T}$ [14]. A recent simulation study also showed that SNR grows super-linearly with frequency, particularly in the deeper regions of the sample; in less deep regions, the SNR versus $\mathrm{B}_{0}$ trend approached linearity [16]. Ultrahigh field imaging has proven particularly beneficial for X-nuclei imaging such as sodium MR, in which a change in $\mathrm{B}_{0}$ from 9.4 to $21.1 \mathrm{~T}$ resulted in an SNR gain of $\sim 3$ compared to a gain of $\sim 2$ for ${ }^{1} \mathrm{H}$ MR [17].

Here, we studied the feasibility of ${ }^{19} \mathrm{~F}$ MRI at $21.1 \mathrm{~T}$ compared to $9.4 \mathrm{~T}$, and the influence of the $\mathrm{B}_{0}$ change on the $\mathrm{SNR}$ and ${ }^{19} \mathrm{~F}$ relaxation of the compound fluoro-15-crown5-ether (PFCE). According to theory and previously published experimental results, we postulated that SNR would increase by a factor of three to four when moving from 9.4 to $21.1 \mathrm{~T}$. We therefore investigated how much of the expected sensitivity gain could be achieved in practical experiments. The rationale behind these experiments was to make use of higher $\mathrm{B}_{0}$ strengths to study inflammatory cell migration with better resolution and detail. Using ${ }^{19} \mathrm{~F}$ MRI and ${ }^{19} \mathrm{~F}$ NPs that label immune cells in vivo, we studied inflammation in experimental autoimmune encephalomyelitis (EAE), the animal model of multiple sclerosis $[6,18]$. The main driving force for using higher $\mathrm{B}_{0}$ is to boost sensitivity and therefore resolution of the in vivo ${ }^{19} \mathrm{~F}$ MR images.

\section{Materials and methods}

\section{Small animal MR scanners}

All experiments were carried out on two small animal MR scanners with different magnetic field strengths: a $21.1 \mathrm{~T}$ vertical bore MR system operating at $900 \mathrm{MHz}\left({ }^{1} \mathrm{H}\right)$ and 844.9 $\mathrm{MHz}\left({ }^{19} \mathrm{~F}\right)$ at the National High Magnetic Field Laboratory (NHMFL) in Tallahassee (Florida, USA) and a $9.4 \mathrm{~T}$ horizontal bore MR system (BioSpec 94/20, Bruker BioSpin MRI, Ettlingen) operating at $400 \mathrm{MHz}\left({ }^{1} \mathrm{H}\right)$ and $376 \mathrm{MHz}$ $\left({ }^{19} \mathrm{~F}\right)$ located in Berlin (Germany). The $21.1 \mathrm{~T}$ magnet was designed and constructed at the NHMFL [19]. It has a bore size of $105 \mathrm{~mm}$ and a 64-mm inner diameter imaging gradients (Resonance Research Inc, Billerica, MA) that provides a peak gradient strength of $6 \mathrm{mT} / \mathrm{cm}$ over a $64-\mathrm{mm}$ diameter [20]. The $9.4 \mathrm{~T}$ system has a bore of $120 \mathrm{~mm}$ and an actively shielded B-GA12 gradient set providing gradient amplitudes of $4 \mathrm{mT} / \mathrm{cm}$. Both MR systems are equipped with a Bruker Avance III console and operated using PV6.1 software (Bruker BioSpin, Ettlingen, Germany).

\section{Radiofrequency (RF) coils and EMF simulations}

Experiments were carried out on the $21.1 \mathrm{~T}$ using a linear low pass (LP) ${ }^{19} \mathrm{~F} /{ }^{1} \mathrm{H}$ birdcage RF coil consisting of eight rungs: coil length $=54.5 \mathrm{~mm}$, inner diameter $=33 \mathrm{~mm}$, shield length $=64 \mathrm{~mm}$, shield diameter $=53 \mathrm{~mm}$. For experiments at the $9.4 \mathrm{~T}$ MR system, a linear high-pass ${ }^{19} \mathrm{~F} /{ }^{1} \mathrm{H}$ RF coil of similar dimensions was used ( 12 rungs, coil length $=50 \mathrm{~mm}$, inner diameter $=35 \mathrm{~mm}$, shield length $=80 \mathrm{~mm}$, shield diameter $=57 \mathrm{~mm}$ ). To estimate the expected SNR gain, electromagnetic field (EMF) simulations were performed for both RF coils using the finite-element method (FEM) implemented in CST Microwave Studio (CST, Darmstadt, Germany). FEM was chosen over a time-domain solver because the unstructured finite-element meshes can more accurately resolve the current distributions occurring on metal structures with singular edges such as copper strips, thus leading to a more accurate loss estimation. Copper and substrate losses were calculated in the 3D domain by the FEM solver based on their respective conductivity and loss tangent values (copper conductivity $\sigma=5.8 \mathrm{e} 7 \mathrm{~S} / \mathrm{m}$, FR 4 $\tan \delta=0.025$ ). Capacitors were assigned equivalent series resistances according to manufacturer datasheets, and solder losses also modeled as frequency-dependent resistors scaled to the desired frequency based on available literature 
data [21]. Both RF coils were loaded with a 15-ml falcon tube phantom filled with tissue equivalent material $(\varepsilon=78$, $\sigma=0.79 \mathrm{~S} / \mathrm{m}$ for $9.4 \mathrm{~T}, \varepsilon=78, \sigma=0.94 \mathrm{~S} / \mathrm{m}$ for $21.1 \mathrm{~T}$ ). Cable losses and preamplifier noise were approximated by appropriate attenuators inserted between the power source and the RF coil in the simulation; attenuation was set according to the losses at the respective frequency $(9.4 \mathrm{~T}: 0.5 \mathrm{~dB}$ preamplifier noise figure, $2 \mathrm{~m}$ cable with $0.58 \mathrm{~dB} / \mathrm{m}$ attenuation; $21.1 \mathrm{~T}: 1 \mathrm{~dB}$ preamp noise figure, $3 \mathrm{~m}$ cable with $0.9 \mathrm{~dB} / \mathrm{m}$ attenuation). The coils were perfectly tuned and matched $\left(\left|S_{11}\right|<-40 \mathrm{~dB}\right)$ and were fed with a forward power of $1 \mathrm{~kW}$, which is dissipated in the system according to the noise power contribution of the different noise sources (Table 1). The average receive field $\left(\mathrm{B}_{1}^{-}\right)$magnitude was calculated in a $5 \times 5 \times 5 \mathrm{~mm}$ cube in the isocenter of the coil. The relative estimated SNR between both systems was then calculated as follows:

$\frac{\mathrm{SNR}_{21.1 \mathrm{~T}}}{\mathrm{SNR}_{9.4 \mathrm{~T}}}=\left(\frac{f_{0 \mid 21.1 \mathrm{~T}}}{f_{0 \mid 9.4 \mathrm{~T}}}\right)^{2} \cdot\left(\frac{B_{1 \mid 21.1 \mathrm{~T}}^{-}}{B_{1 \mid 9.4 \mathrm{~T}}^{-}}\right)$,

where $B_{1}^{-}$is the average receive field strength of each RF coil in $\mu T / \sqrt{k W}[15]$.

\section{Animal experiments}

All experiments were conducted in accordance with the procedures approved by the Animal Welfare Department of the State Office of Health and Social Affairs Berlin (LAGeSo), and conformed to national and international guidelines to

Table 1 Contribution of each noise source to the total noise power

\begin{tabular}{lrl}
\hline Noise Source & $B_{0}(\mathrm{~T})$ & $\begin{array}{l}\text { Noise power } \\
\text { contribution } \\
(\%)\end{array}$ \\
\hline Preamplifier & 9.4 & 11.0 \\
Connection cables & 21.1 & 20.6 \\
Capacitors & 9.4 & 20.9 \\
& 21.1 & 36.8 \\
Copper and housing & 9.4 & 24.8 \\
& 21.1 & 1.1 \\
Sample & 9.4 & 7.8 \\
& 21.1 & 4.3 \\
& 9.4 & 35.5 \\
\hline
\end{tabular}

A forward power of $1 \mathrm{~kW}$ used for simulating the $\mathrm{B}_{1}^{-}$field was dissipated in the system according to the different contributions of these sources to the total noise power. The $9.4 \mathrm{~T}$ coil is just minimally sample noise dominated (35.5\% sample losses vs. $32.6 \%$ intrinsic coil losses), whereas at $21.1 \mathrm{~T}$ sample noise almost completely dominates $(37.1 \%$ vs $5.4 \%)$ minimize discomfort to animals (86/609/EEC). Experimental autoimmune encephalomyelitis (EAE) was actively induced in SJL/J mice as previously described [18]. Female SJL/J mice (Janvier SAS, Le Genest-St-Isle, France) were immunized subcutaneously with $250 \mu \mathrm{g} \mathrm{PLP}_{139-151}$ purity $>95 \%$ (Pepceuticals Ltd., UK) together with Complete Freund's Adjuvant and heat-killed Mycobacterium tuberculosis (H37Ra, Difco). On each day following immunization, mice were weighed and scored as follows: 0 , no disease; 1 , tail weakness and righting reflex weakness; 2 , paraparesis; 3 , paraplegia; 4 , paraplegia with forelimb weakness or paralysis; 5, moribund or dead animal. Five days following EAE induction, mice were administered NPs containing $5 \mu \mathrm{mol}$ of the ${ }^{19} \mathrm{~F}$ compound fluoro-15-crown-5-ether (PFCE) [18]. NPs were prepared by emulsifying $1200 \mathrm{mM}$ PFCE (Fluorochem, UK) with Pluronic F-68 (SigmaAldrich, Germany) using a titanium sonotrode (Sonopuls GM70, Bandelin, Germany), as previously described [22]. NPs were administered daily to EAE mice from day 5 to day 10 after immunization. On day 10 , the mice were transcardially perfused with $20 \mathrm{ml}$ PBS followed by $20 \mathrm{ml} 4 \%$ paraformaldehyde (PFA) following terminal anesthesia, after which the tissue was prepared for ex vivo MRI [18].

\section{Sample preparation}

In this study, we focused on PFCE since this ${ }^{19} \mathrm{~F}$ compound is commonly used to image inflammation and to track cells in vivo. We prepared (1) PFCE phantoms containing only pure PFCE (Setup 1), (2) NPs containing different concentrations of PFCE (Setup 2), (3) inflamed tissue infiltrated by inflammatory cells labeled with PFCE NPs (Setup 3). The same phantoms were used at both $9.4 \mathrm{~T}$ and $21.1 \mathrm{~T} \mathrm{~B}_{0}$ strengths.

For studying PFCE in pure form, we submerged an NMR tube containing pure PFCE in a $15-\mathrm{ml}$ tube filled with water containing $4.5 \mathrm{~g} / \mathrm{L} \mathrm{NaCl}$ (this $\mathrm{NaCl}$ concentration provides the best electrodynamic loading conditions for a $15-\mathrm{ml}$ tube for the RF coils used). For studying PFCE in nanoparticle form, four NMR tubes containing different PFCE concentrations (60 mM, $120 \mathrm{mM}, 600 \mathrm{mM}, 1200 \mathrm{mM}$ PFCE) were submerged in a $50-\mathrm{ml}$ tube containing $4.5 \mathrm{~g} / \mathrm{L} \mathrm{NaCl}$. For studying PFCE in inflamed tissue, we prepared EAE mice that had been transcardially perfused with PBS and $4 \%$ PFA (see above). To examine PFCE in the inflamed central nervous system (CNS), as well as associated lymphatic tissue, the mice were cleared of the external pelt, extremities, and thoracic and abdominal tissues. Brain and spinal cord (CNS) were kept in situ within the skull and vertebral column, keeping head and neck draining lymph nodes (LNs) in the preparation. Other lymphoid tissue such as spleen was also harvested and stored separately in 2-ml tubes containing $4 \%$ PFA. All fixed tissue was stored at $4{ }^{\circ} \mathrm{C}$. CNS/LNs 
preparations were transferred and secured within 15-ml tubes filled with 4\% PFA. Spleens were inserted and secured within NMR tubes to maintain the longitudinal alignment of the tissue along the $\mathrm{z}$-axis $\left(\mathrm{B}_{0}\right.$ field) for both horizontal $(9.4 \mathrm{~T})$ and vertical $(21.1 \mathrm{~T})$ bores. The NMR tubes holding the spleens were then transferred to $15-\mathrm{ml}$ tubes filled with $4.5 \mathrm{~g} / \mathrm{L} \mathrm{NaCl}$. All 15-ml tubes (containing pure compound, CNS/LNs tissue or spleens) were positioned within a 50-ml tube.

\section{MR measurements}

To determine SNR differences in ${ }^{19} \mathrm{~F}$ measurements between the two magnetic field strengths, we made use of two of the above phantom setups (Setup 1 and Setup 2). For the ${ }^{19} \mathrm{~F}$ phantom with pure PFCE (Setup 1) we employed a 2D-FLASH technique with variable repetitions times (TRs) and flip angles (FAs): TR $=14-4000 \mathrm{~ms}, \mathrm{TE}=4.2 \mathrm{~ms}$, $\mathrm{FA}=5^{\circ}-90^{\circ}$, dummy scans $=80$, exc. pulse $=\operatorname{sinc} 10 \mathrm{H}$ $(3000 \mathrm{~Hz}), \mathrm{FOV}=[32 \times 32] \mathrm{mm}^{2}$, matrix $=256 \times 256$, averages $(\mathrm{NA})=6$, TA (acquisition time) $=0.5-30 \mathrm{~min}$ (according to TR). To quantify and compare SNR in a way more relevant for brain inflammation, we measured SNR as a function of the number of ${ }^{19} \mathrm{~F}$ atoms using phantoms containing different concentrations of ${ }^{19} \mathrm{~F}$ nanoparticles and different slice thickness (Setup 2). We acquired axial ${ }^{19} \mathrm{~F}$ MR images using 2D-RARE: TR $=4000 \mathrm{~ms}, \mathrm{TE}=9.1 \mathrm{~ms}$, ETL (echo train length, rare factor) $=4, \mathrm{FOV}=[30 \times 30] \mathrm{mm}^{2}$, matrix $=128 \times 126$, slices $=1-10 \mathrm{~mm}, \mathrm{NA}=1, \mathrm{TA}=17 \mathrm{~min}$.

Parametric mapping was performed on axial slices of Setup 1 and Setup 2, as well as coronal slices of Setup 3 (EAE spleen tissue) to determine $T_{1}$ and $T_{2}$ of PFCE. A RARE sequence with variable repetition times (RAREVTR) was used for $T_{1}$-mapping. A multi-spin echo (MSE) technique was employed for $T_{2}$-mapping. For Setup 1 (pure PFCE) we used the following parameters for RAREVTR: $14 \mathrm{TRs}=29-5000 \mathrm{~ms}, \mathrm{TE}=5.6 \mathrm{~ms}, \mathrm{ETL}=4$, FOV $=[20 \times 20] \mathrm{mm}^{2}$, matrix $=144 \times 144$, slice thickness $=5 \mathrm{~mm}, \mathrm{NA}=2, \mathrm{TA}=17 \mathrm{~min}$; for MSE: $\mathrm{TR}=30 \mathrm{~s}, 40$ $\times$ TEs $=160-6400 \mathrm{~ms}$, FOV $=[20 \times 20] \mathrm{mm}^{2}$, matrix $=96$ $\times 96$, slice thickness $=10 \mathrm{~mm}, \mathrm{NA}=4, \mathrm{TA}=3 \mathrm{~h} 12 \mathrm{~min}$. For Setup 2 (PFCE nanoparticles) we used the following parameters for RARE-VTR: $15 \mathrm{TRs}=24-8000 \mathrm{~ms}, \mathrm{TE}=4.6 \mathrm{~ms}$, $\mathrm{ETL}=4, \mathrm{FOV}=[30 \times 30] \mathrm{mm}^{2}$, matrix $=96 \times 96$, slice thickness $=10 \mathrm{~mm}, \mathrm{NA}=36, \mathrm{TA}=5 \mathrm{~h} 42 \mathrm{~m}$; for MSE: $\mathrm{TR}=4000 \mathrm{~ms}, 150 \mathrm{TEs}=7-1050 \mathrm{~ms}, \mathrm{FOV}=[30 \times 30]$ $\mathrm{mm}^{2}$, matrix $=96 \times 96$, slice thickness $=10 \mathrm{~mm}, \mathrm{NA}=64$, $\mathrm{TA}=6 \mathrm{~h} 49 \mathrm{~min}$. For Setup 3 (spleens from EAE mice administered with nanoparticles) we acquired different repetitions of the same coronal spleen slice using RARE-VTR: 9 TRs $=50-12000 \mathrm{~ms}, \mathrm{TE}=6.9 \mathrm{~ms}, \mathrm{ETL}=4, \mathrm{FOV}=[20 \times 30]$ $\mathrm{mm}^{2}$, matrix $=44 \times 64$, slice thickness $=3.6 \mathrm{~mm}, \mathrm{NA}=128$, $\mathrm{TA}=15$ h $50 \mathrm{~min}$.
For visualizing inflammation in the EAE mouse CNS and associated lymph nodes, we acquired ${ }^{1} \mathrm{H}$ MR images using 3D-FLASH: $\mathrm{TR}=150 \mathrm{~ms}$, TE $=7.5 \mathrm{~ms}, \mathrm{FOV}=30 \times$ $20 \times 20 \mathrm{~mm}$, matrix $=600 \times 400 \times 400, \mathrm{NA}=2, \mathrm{TA}=3 \mathrm{~h}$ $20 \mathrm{~min}$ and ${ }^{19} \mathrm{~F}$ MR images at different spatial resolutions using 3D-RARE: $\mathrm{TR}=800 \mathrm{~ms}, \mathrm{TE}=4.9 \mathrm{~ms}, \mathrm{FOV}=30 \times$ $20 \times 20 \mathrm{~mm}, \mathrm{NA}=256$, high-resolution: matrix $=195 \times$ $130 \times 130, \mathrm{ETL}=33, \mathrm{TA}=7 \mathrm{~h} 30 \mathrm{~min}$; medium-resolution: matrix $=135 \times 90 \times 90, \mathrm{ETL}=23, \mathrm{TA}=5 \mathrm{~h} 14 \mathrm{~min}$; low-resolution: matrix $=90 \times 60 \times 60, \mathrm{ETL}=15, \mathrm{TA}=3 \mathrm{~h} 24 \mathrm{~min}$.

\section{Data analysis}

SNR was calculated using MATLAB ${ }^{\circledR}(\mathrm{R} 2018 \mathrm{a}$, The Mathworks, Natick, USA) by dividing the signal from magnitude images $\left(S_{\mathrm{m}}\right)$ by the standard deviation of the background $\left(\sigma_{\mathrm{m}}\right)$. For both Setup 1 and Setup 2, a single SNR value was determined from the mean signal intensity over one central circular regions of interest covering $~ 90 \%$ of visible sample and the standard deviation of the noise of four region of interests positioned at the corners of the image. SNR was corrected to compensate for the non-Gaussian distribution [23]. For both single channel RF coils used, the intensity values of the MR images are expected to follow a Rician distribution $[24,25]$. We estimated the true SNR from the $S_{\mathrm{m}}$ and background $\sigma_{\mathrm{m}}$ using:

$\mathrm{SNR}=\frac{S}{\sigma}=\frac{S_{\mathrm{m}}}{\sigma_{\mathrm{m}}} \cdot \frac{f_{\mathrm{S}}\left(S_{\mathrm{m}}, \sigma_{\mathrm{m}}\right)}{1 / c_{\sigma}}$,

where $c_{\sigma}$ is 0.655 (for Rician distribution) and the correction function $f_{\mathrm{S}}$ is derived from the mean of the respective distribution $[24,26]$. The noise-induced signal bias of the conventional Fourier reconstructed images was corrected [24]. All image reconstructions were thresholded to $3.5 \sigma$ to distinguish between background and signal voxels. The number of ${ }^{19} \mathrm{~F}$ atoms per image pixel was estimated from the PFCE concentration and the voxel size, and plotted against the SNR. Two-factor ANOVA was used to compare SNR (dependent variable) at various numbers of fluorine atoms between the two field strengths (independent variables). GraphPad Prism v.5.01 (GraphPad Software, Inc. La Jolla, CA, USA) was used for the analysis. SNR efficiency $\left(\mathrm{SNR}_{\mathrm{eff}}\right)$ for 2D-FLASH data was calculated as follows [27]:

$\mathrm{SNR}_{\mathrm{eff}}=\frac{\mathrm{SNR}}{\sqrt{\mathrm{NA} \times \mathrm{TR}}}$

Calculations of PFCE $T_{1}$ and $T_{2}$ relaxation times were performed on MSE and RARE-VTR scans using parametric mapping developed in MATLAB ${ }^{\circledR}$ in-house. $T_{1}$ and $T_{2}$ were determined by fitting the following relation [28] to the obtained data points using least-squares optimization: 
$S_{(\mathrm{TR})}=S_{0} \cdot\left(1-\exp \left(\frac{-\mathrm{TR}}{T_{1}}\right)\right)$

$S_{\text {(TE) }}=S_{0} \cdot \exp \left(\frac{-\mathrm{TE}}{T_{2}}\right)$,

where $S_{(\mathrm{TR})}$ and $S_{(\mathrm{TE})}$ are the signal intensity at a specific repetition time and specific echo time, respectively, $S_{0}$ is the maximum signal and TR and TE are a specific repetition time and specific echo time, respectively. Depending on the experiments, relaxation times were calculated either as pixel-based data points or averaged data within specific regions of interest, corrected for the non-Gaussian noise distribution in MR magnitude images [24].

Calculations of $T_{1}$ relaxation time for PFCE were also performed on 2D-FLASH acquisitions with different TRs and FAs $(\alpha) . T_{1}$ was calculated from the Ernst equation [29]:

$S_{(\mathrm{TR}, \alpha)}=S_{0, \alpha} \cdot \sin \cdot \frac{1-\exp \left(-\mathrm{TR} / T_{1}\right)}{1-\cos \exp \left(-\mathrm{TR} / T_{1}\right)}$,

where $S_{(\mathrm{TR}, \alpha)}$ is signal intensity at a specific repetition time and flip angle $(\alpha)$ and $S_{(0, \alpha)}$ is the maximum signal intensity at a specific $\alpha$.

For a 3D representation of ${ }^{19} \mathrm{~F}^{1} \mathrm{H}$ MR image overlays of Setup 3 (EAE mouse brain and associated lymph nodes), ${ }^{1} \mathrm{H}$ MR data were first converted to NIFTI-format in ImageJ (National Institutes of Health, USA, http://imagej.nih.gov/ ij and ${ }^{1} \mathrm{H}$ MR images of inflamed regions (CNS) and draining lymph nodes were segmented using ITK snap (version 3.4) [30].

\section{Results}

\section{Estimation of noise contribution and SNR gain from 9.4 to $21.1 \mathrm{~T}$}

Prior to performing the practical experiments, we estimated the SNR gain to be expected at $21.1 \mathrm{~T}$ from simulations. We first studied the noise contributions for both the $9.4 \mathrm{~T}$ and 21.1 T MR systems. The intrinsic noise contribution of the RF coil (capacitors, copper and housing) compared to the total noise power (Table 1) showed that the $9.4 \mathrm{~T}$ coil was only slightly more sample noise dominated (35.5\% sample vs. $32.6 \%$ intrinsic coil losses). The intrinsic noise contribution of the $21.1 \mathrm{~T}$ coil is lower: in contrast to the $9.4 \mathrm{~T}$ coil, the sample noise dominates over the coil noise contribution (37.1\% sample vs. $5.4 \%$ intrinsic coil losses). At $21.1 \mathrm{~T}$, the noise contributed by the total cable length (between preamplifier and coil) as well as preamplifier noise appeared to be higher, almost double that of the $9.4 \mathrm{~T}$ system. For birdcage coils, as used in this study, the transmit field $\left(\mathrm{B}_{1}{ }^{+}\right)$is expected to be approximately equal to the receive field $\left(\mathrm{B}_{1}{ }^{-}\right)$. From the simulations we calculated an average $\mathrm{B}_{1}{ }^{-}$field strength of $288 \mu \mathrm{T}$ at $9.4 \mathrm{~T}$ and $153 \mu \mathrm{T}$ at $21.1 \mathrm{~T}$, for a forward power of $1 \mathrm{~kW}$. Using the principle of reciprocity [15], and ignoring all flip angle, sequence and relaxationdependent effects, the expected SNR ratio was calculated as 2.68 using Eq. (1). This ratio represents a baseline estimation of the expected SNR gain, based on the information available for the specific hardware of each system. Additionally, one can estimate the SNR gain between the two systems by considering the relationship of the individual reference powers required for calibrating a $90^{\circ}$ flip angle. The reference power required at $9.4 \mathrm{~T}$ and $21.1 \mathrm{~T}$ was $0.257 \mathrm{~W}$ and $0.338 \mathrm{~W}$, respectively. This translates to a field magnitude of $12.3 \mu T / \sqrt{k W}$ at $9.4 \mathrm{~T}$ and $9.3 \mu T / \sqrt{k W}$ at $21.1 \mathrm{~T}$. The ratio between the two field magnitudes $(0.76)$ can be used as a scaling factor in Eq. (1) to calculate SNR gain from the quadratically increasing MR signal strength. This yields an estimated SNR gain of $\sim 3.8$, when reference power is factored into the Eq. (1).

\section{Experimental SNR difference between 9.4 $\mathrm{T}$ and 21.1 T}

To determine the actual SNR gain we acquired axial ${ }^{19} \mathrm{~F}$ MR scans of a nanoparticle phantom (Setup 2) containing four different concentrations of PFCE (Fig. 1a). We used a 2D-RARE sequence with variable slice thicknesses (1-10 mm, in steps of $0.5 \mathrm{~mm})$. This together with the four different PFCE concentrations resulted in a total of 76 experiments to estimate SNR as a function of the number of ${ }^{19} \mathrm{~F}$ atoms per voxel for both $\mathrm{B}_{0}$ strengths. Figure 1a illustrates 20 of these SNR experiments (only 5 slice thicknesses are shown). Results of all SNR experiments were then plotted against the number of ${ }^{19} \mathrm{~F}$ atoms per voxel for both $\mathrm{B}_{0}$ strengths (Fig. 1b). There was a significant difference in the SNR for all 76 experiments between the two $\mathrm{B}_{0}$ strengths observed at varying numbers of fluorine atoms $(p<0.0001$, two-factor ANOVA). A mean SNR gain of 2.1 was estimated. For these experiments, we used a long TR in the 2D-RARE method to measure SNR differences between $\mathrm{B}_{0}$ strengths.

In the next experiments, we studied the dependency of the actual SNR gain on the TR and flip angle $(\alpha)$ at both $\mathrm{B}_{0}$ strengths. Axial ${ }^{19} \mathrm{~F}$ MR scans of the pure PFCE compound (Setup 1) were acquired using a wide range of TRs $(14-4000 \mathrm{~ms})$ and $\alpha\left(5^{\circ}-90^{\circ}\right)$. SNR changes over the relaxation period were studied and the $T_{1}$ relaxation values for both $\mathrm{B}_{0}$ strengths determined (Fig. 2). A 2-D fit of the measured data points resulted in $T_{119.4 \mathrm{~T}}=788 \mathrm{~ms}$ (Fig. 2a) and $T_{121.1 \mathrm{~T}}=409 \mathrm{~ms}$ (Fig. $2 \mathrm{~b}$ ). The choice of TR has a 
Fig. 1 Comparison of SNR between 21.1 and $9.4 \mathrm{~T} \mathrm{~B}_{0}$ strengths in PFCE nanoparticles using a 2D-RARE sequence. a SNR was calculated from axial images of four NMR tubes (60 mM, $120 \mathrm{mM}, 600 \mathrm{mM}$, $1200 \mathrm{mM}$ ) with varying slice thicknesses (shown are MR images of 1, 2, 4, 6 and $8 \mathrm{~mm}$ slice thickness). SNR was calculated by dividing signal from magnitude images by the background standard deviation, and corrected to compensate for the non-Gaussian Rician distribution. b Plot of SNR versus ${ }^{19} \mathrm{~F}$ atoms per voxel. A linear fit was determined for both $21.1 \mathrm{~T}$ $\left(y=4 \mathrm{e}-19 x, R^{2}=0.9983\right)$ and $9.4 \mathrm{~T}\left(y=2 \mathrm{e}-19 x, \mathrm{R}^{2}=0.9996\right)$. A significant difference was determined between 9.4 and $21.1 \mathrm{~T}, p<0.0001$, two-factor ANOVA
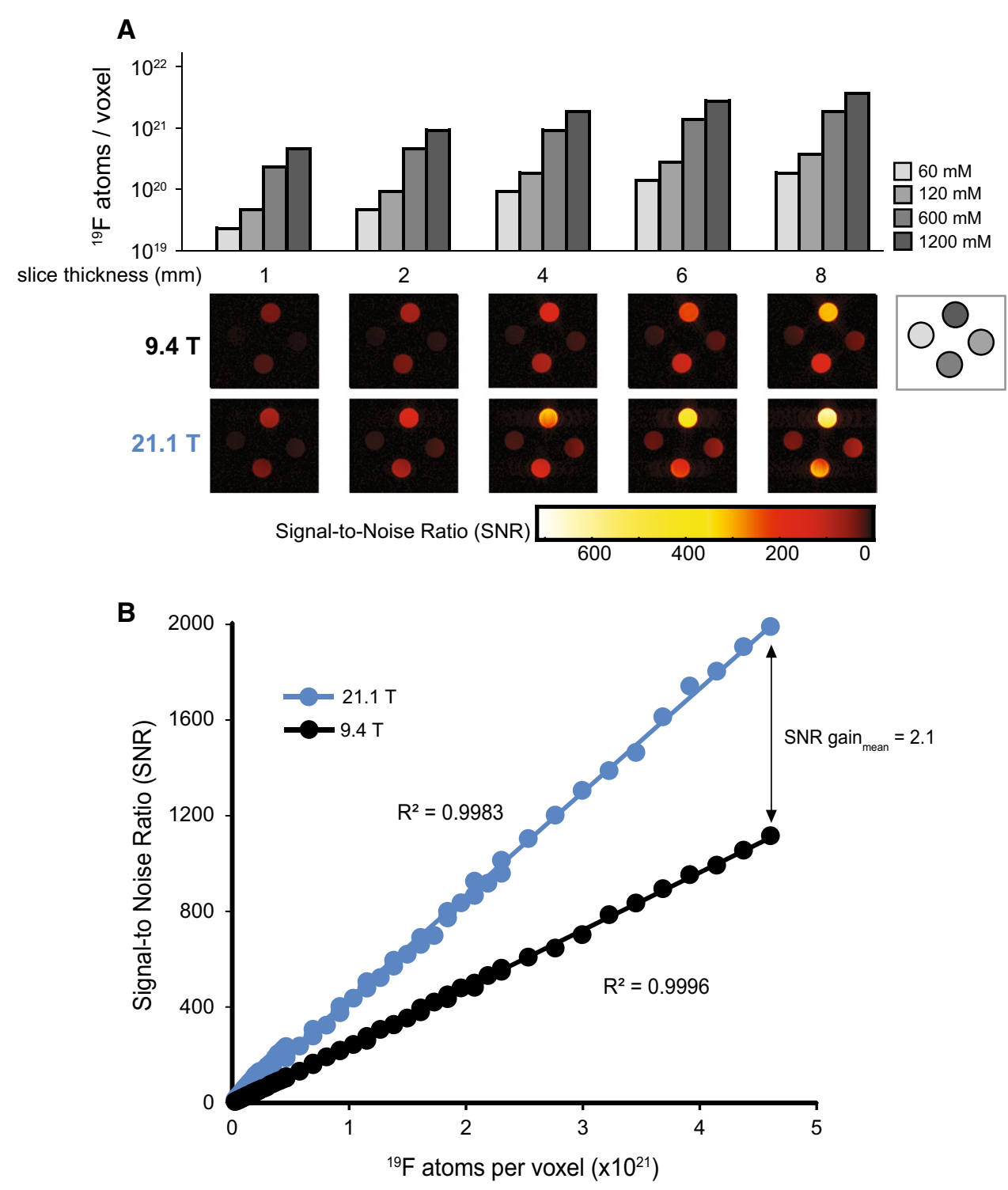

direct impact on the total acquisition time. A shorter TR permits more averages to be acquired in the same time period. To take this into consideration we estimated the SNR achievable in a fixed amount of time [27] (SNR efficiency $=\mathrm{SNR} / \sqrt{t}$ ) from the data obtained at $9.4 \mathrm{~T}$ (Fig. 2c) and 21.1 T (Fig. 2d). For all scans with TR shorter than $4 \mathrm{~s}$, we calculated how many averages would be possible within the fixed acquisition time, and then added the corresponding SNR improvement, based on the theoretical relationship $\mathrm{SNR} \sim \sqrt{\mathrm{NA}}$. As expected, $\mathrm{SNR} / \sqrt{t}$ favors very short TRs for both $\mathrm{B}_{0}$ strengths. The maximal SNR $/ \sqrt{t}$ for $9.4 \mathrm{~T}$ was calculated to be $96 / \sqrt{\min }$ at $\mathrm{TR}=20 \mathrm{~ms}$ and $\alpha=13^{\circ}$, while the maximal SNR $/ \sqrt{t}$ for $21.1 \mathrm{~T}$ was calculated to be $701 / \sqrt{\mathrm{min}}$ at $\mathrm{TR}=20 \mathrm{~ms}$ and $\alpha=18^{\circ}$. At the optimal condition for 9.4 T, i.e., TR $=20 \mathrm{~ms}$ and $\alpha=13^{\circ}$, the SNR $/ \sqrt{t}$ for $21.1 \mathrm{~T}$ was calculated to be $668 / \sqrt{\mathrm{min}}$. The $\mathrm{SNR} / \sqrt{t}$ ratio (between $21.1 \mathrm{~T}$ and $9.4 \mathrm{~T}$ ) at these conditions is therefore
6.95 , while the $\mathrm{SNR} / \sqrt{t}$ ratio when comparing the best possible conditions for $21.1 \mathrm{~T}$ with the best possible conditions for $9.4 \mathrm{~T}$ is estimated to be 7.29 . The $\mathrm{SNR} / \sqrt{t}$ ratio will vary between the two $\mathrm{B}_{0}$ strengths, according to the specific $\alpha$ and TR chosen for the particular experimental setup. Within a sensible range of $\alpha\left(1^{\circ}-90^{\circ}\right)$ and TR $(15-4000 \mathrm{~ms})$, the minimum $\mathrm{SNR} / \sqrt{t}$ ratio would be 5.5 (at $\mathrm{TR}=4000 \mathrm{~ms}$, $\alpha=1^{\circ}$ ) and the maximum would be 10.0 (at TR $=15 \mathrm{~ms}$, $\alpha=90^{\circ}$ ). However, these results illustrate the $\mathrm{SNR} / \sqrt{t}$ ratio due to changes in both $\mathrm{B}_{0}$ and $T_{1}$. To distinguish between both influencing factors, we modeled the SNR $\sqrt{t}$ at $21.1 \mathrm{~T}$ for the $T_{1}$ observed at $9.4 \mathrm{~T}\left(T_{1 \mid 21.1 \mathrm{~T}}=T_{1 \mid 9.4 \mathrm{~T}}=788 \mathrm{~ms}\right)$. With this we could determine the $\mathrm{B}_{0}$ effect on SNR efficiency independent of $T_{1}$ effects (Fig. 3): the maximal SNR $/ \sqrt{t}$ for $21.1 \mathrm{~T}$ was calculated to be $505 / \sqrt{\mathrm{min}}$ at $\mathrm{TR}=20 \mathrm{~ms}$ and $\alpha=13^{\circ}$, in comparison to the $96 / \sqrt{\min }$ at the same TR and 

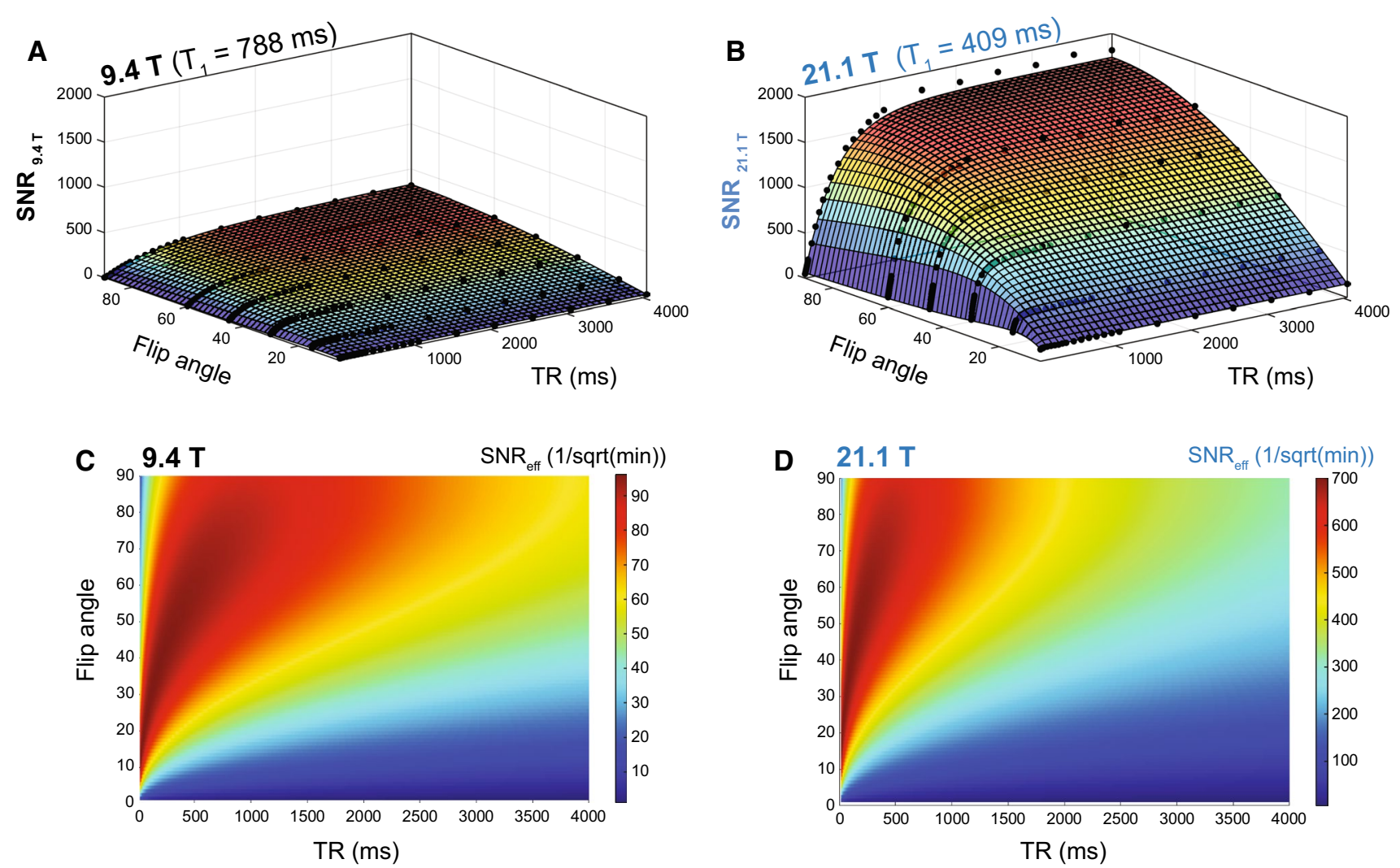

Fig. 2 Comparison of SNR between 21.1 $\mathrm{T}$ and 9.4 $\mathrm{T} \mathrm{B}_{0}$ strengths for pure PFCE using a 2D-FLASH sequence. SNR measurements at various repetition times (TR $=14-4000 \mathrm{~ms})$ and flip angles $\left(\alpha=5^{\circ}-90^{\circ}\right)$ for both $9.4 \mathrm{~T}$ (a) and $21.1 \mathrm{~T}$ (b) $\mathrm{B}_{0}$ strengths. 2-D fitting of these

data points resulted in $T_{119.4 \mathrm{~T}}=778 \mathrm{~ms}$ and $T_{1121.1 \mathrm{~T}}=409 \mathrm{~ms}$. SNR efficiency $(\mathrm{SNR} / \sqrt{t})$ defined as the SNR achievable in a fixed amount of time was estimated for data obtained at $9.4 \mathrm{~T}$ (c) and $21.1 \mathrm{~T}$ (d)
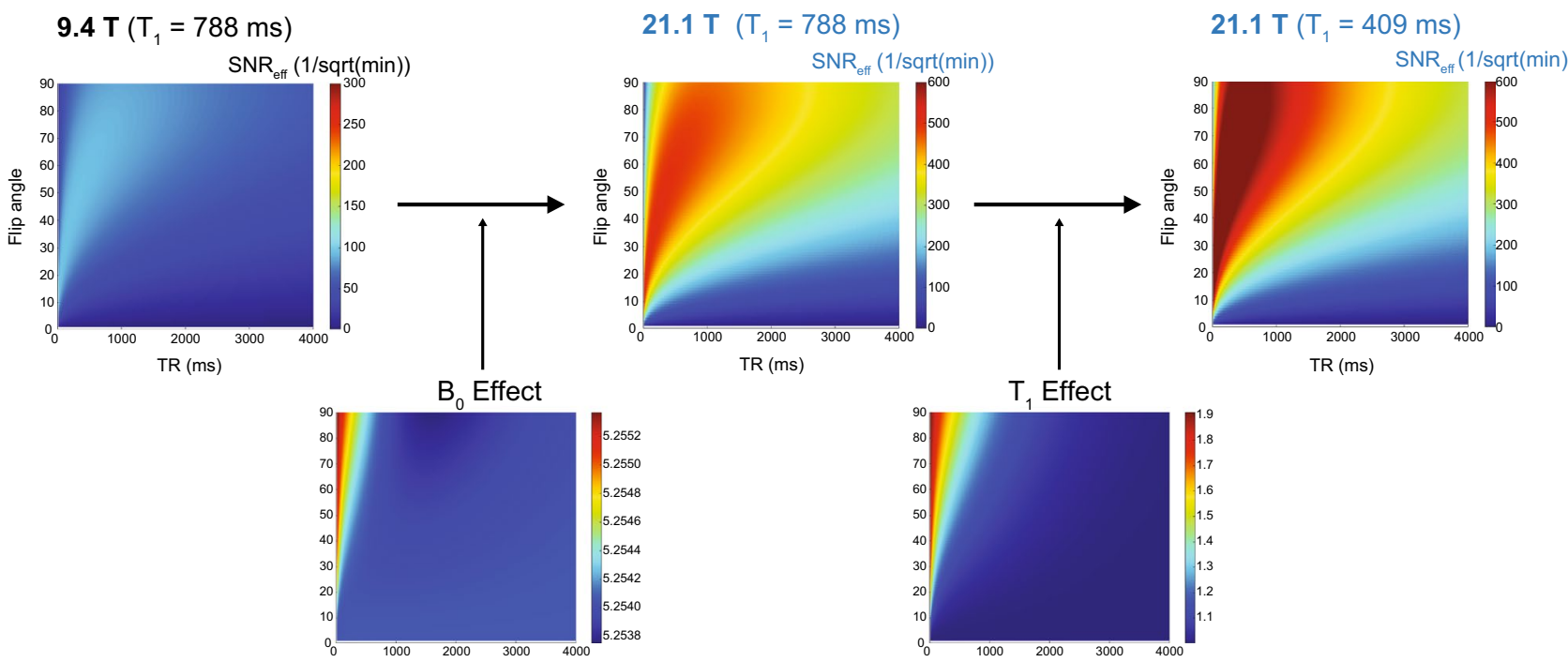

Fig. 3 SNR efficiency changes between $21.1 \mathrm{~T}$ and $9.4 \quad \mathrm{~T} \quad \mathrm{~B}_{0}$ strengths for PFCE as a result of $\mathrm{B}_{0}$ and $T_{1}$ effects. The $\mathrm{B}_{0}$ factor on SNR efficiency at $21.1 \mathrm{~T}$ was calculated to be 5.25 after mod- eling SNR $/ \sqrt{t}$ to keep $T_{1}$ between both magnetic fields constant $\left(T_{121.1 \mathrm{~T}}=T_{119.4 \mathrm{~T}}=788 \mathrm{~ms}\right)$. The $T_{1}$ factor on SNR efficiency at $21.1 \mathrm{~T}$ was calculated to be 1.3 
$\alpha$ for $9.4 \mathrm{~T}$. This translates into an $\mathrm{SNR} / \sqrt{t}$ ratio of 5.25 in comparison to 6.95 (when $T_{1}$ relaxation effects at $21.1 \mathrm{~T}$ were considered, $T_{1121.1 \mathrm{~T}}=409 \mathrm{~ms}$ ). In consequence, the $T_{1}$ shortening at $21.1 \mathrm{~T}$ results in an additional increase in SNR efficiency by a factor of 1.3 (Fig. 3).

We recently reported on the sensitivity gain achieved when comparing a cryogenically cooled ${ }^{19} \mathrm{~F}$ RF probe $\left({ }^{19} \mathrm{~F}\right.$ $\mathrm{CRP}$ ) with a room temperature ${ }^{19} \mathrm{~F}$ RF coil of similar size [18]. Here, we attempted to compare the sensitivity gain achieved when moving from $9.4 \mathrm{~T}$ to $21.1 \mathrm{~T}$ with that achieved by using the ${ }^{19} \mathrm{~F}$ CRP (Fig. 4). Although the two volume resonators used in the $\mathrm{B}_{0}$ comparison were designed for the mouse body, the two RF coils used to determine SNR gains with the ${ }^{19} \mathrm{~F}$ CRP were designed for the mouse head (Fig. 4, left panels). For all four RF coil configurations, we studied the SNR of the same phantom (pure PFCE, Setup 1) employing the parameters $\mathrm{TR}=18.4 \mathrm{~ms}$ and $\alpha=15^{\circ}$, which are close to the conditions calculated to give the best $\mathrm{SNR} / \sqrt{t}$ for the same sequence. The ${ }^{19} \mathrm{~F} \mathrm{CRP}$ is a transceive surface RF coil and does not achieve a spatially uniform excitation [18]. When studying the $\mathrm{B}_{1}$ characteristics of this coil, a strong FA decrease is observed with increasing distance from the ${ }^{19} \mathrm{~F}$ CRP surface [18]. In the previous experiments, we used one NMR tube with PFCE in the middle of the phantom. For the RT versus CRP comparison, we used two NMR tubes with PFCE to study the SNR gain at regions distal and proximal to the ${ }^{19} \mathrm{~F}$ CRP surface. While the factor in the SNR change for the $\mathrm{B}_{0}$ comparison was 6.59, the factor in SNR change from RT to ${ }^{19} \mathrm{~F} \mathrm{CRP} \mathrm{was} 7.49$ when measuring proximal to the ${ }^{19} \mathrm{~F} \mathrm{CRP}$ surface (upper ROI) and 0.93 when measuring distal to the ${ }^{19} \mathrm{~F} \mathrm{CRP} \mathrm{(lower}$ ROI) (Fig. 4).

\section{Relaxation times of PFCE at 9.4 T and 21.1 T}

From the previous experiments, it was evident that $T_{1}$ relaxation was influenced by $\mathrm{B}_{0}$. We next studied the impact of increasing $\mathrm{B}_{0}$ to $21.1 \mathrm{~T}$ on both the $T_{1}$ and $T_{2}$ relaxation for PFCE nanoparticles. Similar to other nuclei, the transverse spin-spin $\left(T_{2}\right)$ relaxation was decreased when moving from 9.4 $\mathrm{T}$ to $21.1 \mathrm{~T}$ (Fig. 5a). The PFCE concentration did not influence changes in the $T_{2}$ values of the nanoparticles at either $\mathrm{B}_{0}$ strengths (Table 2$)$. The longitudinal spin-lattice $\left(T_{1}\right)$ relaxation time of PFCE nanoparticles was substantially shorter at $21.1 \mathrm{~T}$, approximately $50 \%$ compared to $9.4 \mathrm{~T}$ (Fig. $5 \mathrm{~b}$ ). $T_{1}$
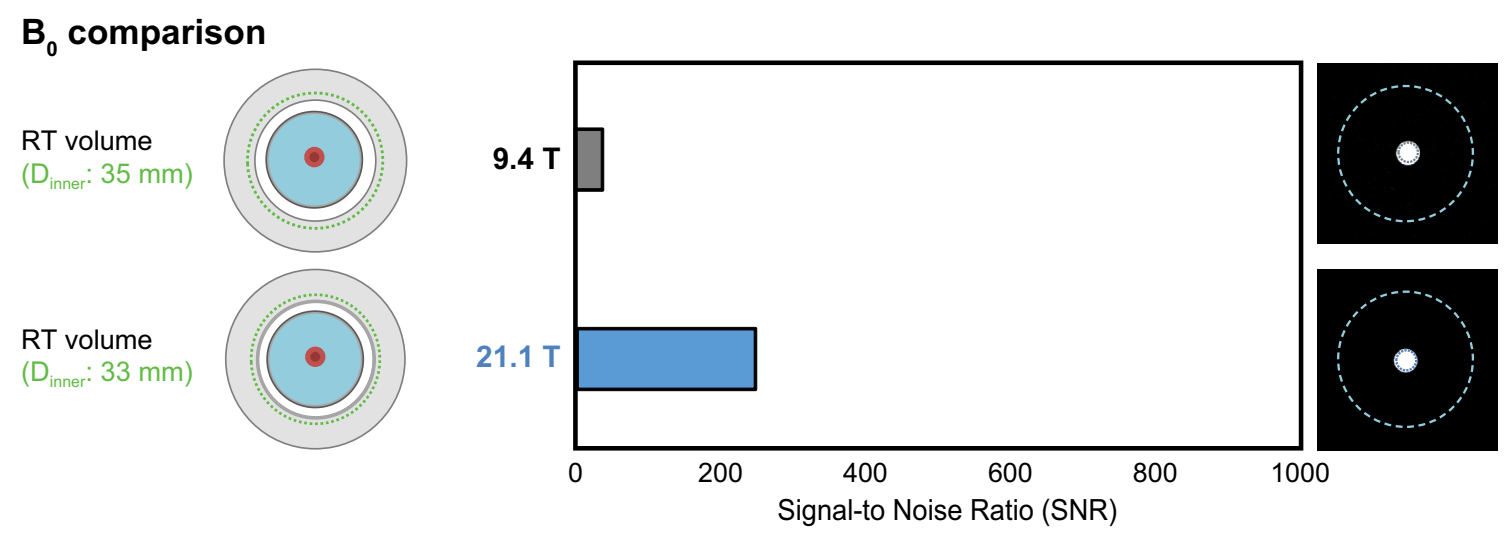

RT versus CRP comparison

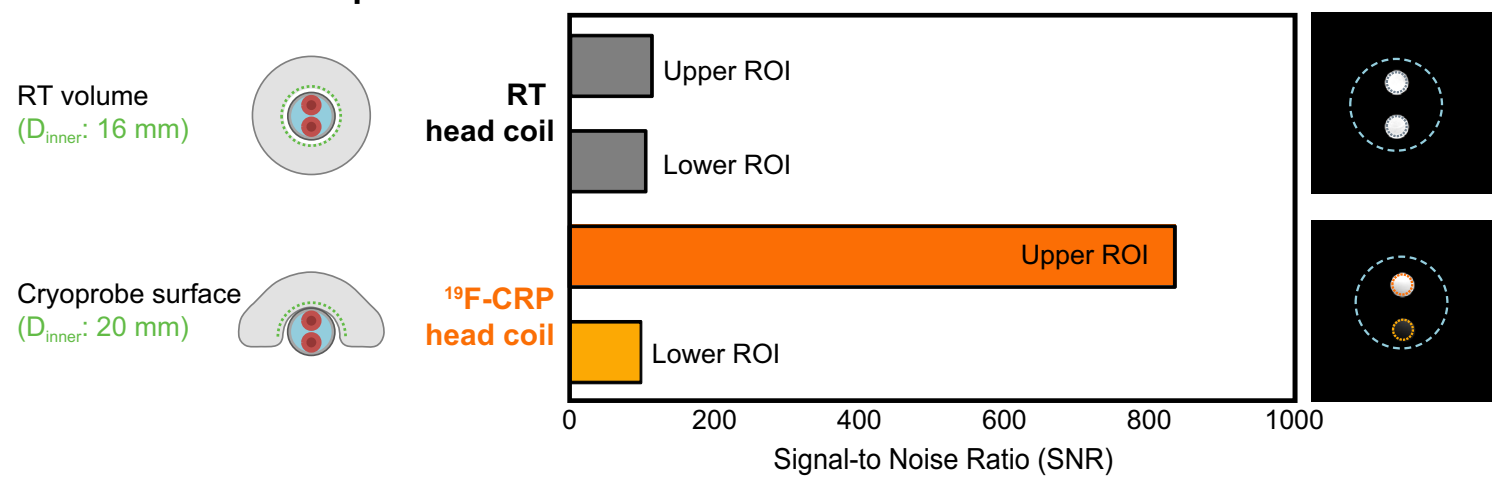

Fig. $4{ }^{19} \mathrm{~F}$ MR sensitivity gain differences between the $\mathrm{B}_{0}$ comparison from 9.4 to $21.1 \mathrm{~T}$ and a RT versus ${ }^{19} \mathrm{~F}$ CRP comparison. Upper panel: $\mathrm{B}_{0}$ comparison between 9.4 and $21.1 \mathrm{~T}$ using room tempera- ture (RT) ${ }^{19} \mathrm{~F}$ mouse body volume resonators with a diameter of 33-35 mm. Lower panel: RT versus CRP comparison using a RT ${ }^{19} \mathrm{~F}$ mouse head coil and a ${ }^{19} \mathrm{~F} \mathrm{CRP}$ 
Fig. $5{ }^{19}$ F relaxation times for PFCE nanoparticles measured at $21.1 \mathrm{~T}$ and $9.4 \mathrm{~T}$. a $T_{2}$ relaxation of PFCE nanoparticles at 21.1 $\mathrm{T}$ was shorter than $T_{2}$ relaxation at $9.4 \mathrm{~T}\left(T_{2121.1 \mathrm{~T}}=195 \mathrm{~ms}\right.$ $\left.T_{2 \mid 9.4 \mathrm{~T}}=503 \mathrm{~ms}\right) . \mathbf{b} T_{1}$ relaxation of PFCE nanoparticles at $21.1 \mathrm{~T}$ was shorter than $T_{1}$ relaxation at $9.4 \mathrm{~T}\left(T_{1 \mid 21.1 \mathrm{~T}}=441 \mathrm{~ms}\right.$; $\left.T_{119.4 \mathrm{~T}}=913 \mathrm{~ms}\right)$
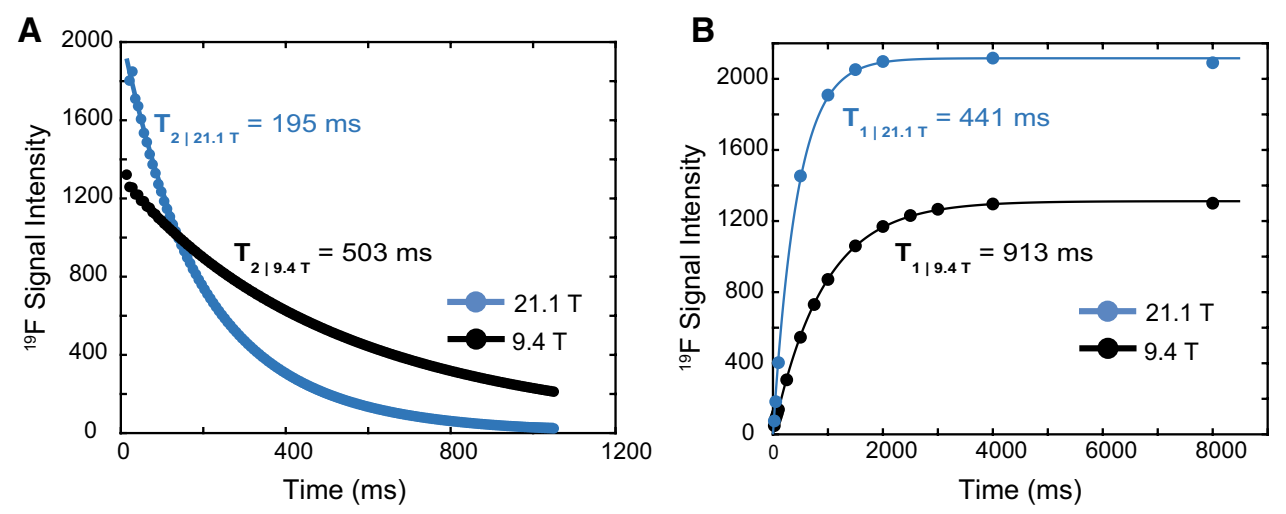

Table 2 No influence of PFCE concentration on $\mathrm{T}_{1}$ and $\mathrm{T}_{2}$ in ${ }^{19} \mathrm{~F}$ nanoparticles

\begin{tabular}{lllll}
\hline PFCE concentration & $1200 \mathrm{mM}$ & $600 \mathrm{mM}$ & $120 \mathrm{mM}$ & $60 \mathrm{mM}$ \\
\hline$T_{2 \mid 9.4 \mathrm{~T}}(\mathrm{~ms})$ & 500 & 350 & 580 & 535 \\
$T_{1 \mid 9.4 \mathrm{~T}}(\mathrm{~ms})$ & 910 & 920 & 925 & 950 \\
$T_{2 \mid 21.1 \mathrm{~T}}(\mathrm{~ms})$ & 195 & 105 & 185 & 230 \\
$T_{1 \mid 21.1 \mathrm{~T}}(\mathrm{~ms})$ & 440 & 445 & 495 & 460 \\
\hline
\end{tabular}

PFCE concentration in the ${ }^{19} \mathrm{~F}$ nanoparticles did not influence $T_{1}$ and $T_{2}$ values. Both $T_{1}$ and $T_{2}$ values for PFCE nanoparticles were influenced by $B_{0}$ strength, but neither value was influenced by changes in the ${ }^{19} \mathrm{~F}$ content at either $\mathrm{B}_{0}$ strength

Table $3 \mathrm{~T}_{1}$ shortening at $21.1 \mathrm{~T}$ is consistent in all PFCE samples studied

\begin{tabular}{lrc}
\hline Sample & $B_{0}(\mathrm{~T})$ & $T_{1}(\mathrm{~ms})$ \\
\hline Pure PFCE & 9.4 & 855 \\
& 21.1 & 435 \\
PFCE nanoparticles $(1200 \mathrm{mM})$ & 9.4 & 915 \\
& 21.1 & 440 \\
Ex vivo EAE spleen & 9.4 & 1005 \\
& 21.1 & 400 \\
\hline
\end{tabular}

Decrease in $T_{1}$ at $21.1 \mathrm{~T}$ is observed consistently for PFCE in all forms tested, as pure compound, in nanoparticle form or in ex vivo tissue from EAE mice that had been administered with PFCE nanoparticles

values were also not influenced by the PFCE concentration in the nanoparticles (Table 2). Shortening of the $T_{1}$ at higher $\mathrm{B}_{0}$ strengths is not common for ${ }^{1} \mathrm{H}$, where $T_{1}$ values are typically known to increase with increasing $\mathrm{B}_{0}[31,32]$. The shortening of $T_{1}$ for PFCE at $21.1 \mathrm{~T}$ was consistent for different forms of the ${ }^{19} \mathrm{~F}$ compound (Table 3 ). The $50 \%$ decrease in $T_{1}$ was observed in the pure compound (Fig. 2a), PFCE nanoparticles (Fig. 5b) and in ex vivo tissue from EAE mice administered PFCE nanoparticles (Fig. 6).

\section{High spatially resolved ${ }^{19} \mathrm{~F}$ MR imaging of EAE inflammation}

To utilize the SNR gain observed in the above experiments to maximum advantage within the context of neuroinflammation, we investigated the feasibility of ${ }^{19} \mathrm{~F}$ MR imaging at $21.1 \mathrm{~T}$ to detect brain inflammation in EAE at high spatial resolutions (Fig. 7). We observed a high level of detail of immune cell distribution in the inflamed brain and accompanying draining lymph nodes. Employing a resolution of $150 \mu \mathrm{m}^{3}$ at $21.1 \mathrm{~T},{ }^{19} \mathrm{~F}$ MR signals were observed especially localized to the brain parenchyma (Fig. 7a). At this spatial resolution, these ${ }^{19} \mathrm{~F}$ signals were not observed at 9.4 $\mathrm{T}$ when using a smaller room temperature coil [18]. When using the same RF coils employed in the present study to compare ${ }^{19} \mathrm{~F}$ MR images in EAE mice, we observed even larger differences between $9.4 \mathrm{~T}$ and $21.1 \mathrm{~T}$; even at low and medium spatial resolutions $\left(222 \mu \mathrm{m}^{3}\right.$ and $\left.333 \mu \mathrm{m}^{3}\right)$ most ${ }^{19} \mathrm{~F}$ MR signals detected at $21.1 \mathrm{~T}$ were no longer identified at $9.4 \mathrm{~T}$ (Supplementary Figure). Given the highly homogeneous field provided by the RF coil used at $21.1 \mathrm{~T}$, we could equally observe very prominent ${ }^{19} \mathrm{~F}$ MR signals within the draining lymph nodes in the ventral region of the EAE mouse head.

\section{Discussion}

In this study, we demonstrate the feasibility and increased sensitivity of ${ }^{19} \mathrm{~F}$ MR methods at $21.1 \mathrm{~T}$ for detecting inflammation with high spatial definition in the brain and adjacent lymphatic system in the animal model of multiple sclerosis. The potential applications of ${ }^{19} \mathrm{~F}$ MR methods to image inflammation have long been recognized $[1-5,7]$, even in autoimmune encephalomyelitis $[6,33,34] .{ }^{19} \mathrm{~F}$ MR methods 
A

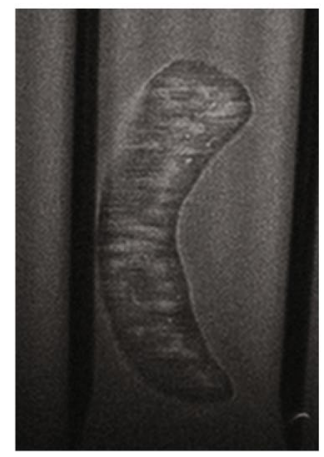

${ }^{1} \mathrm{H}$ MRI
B

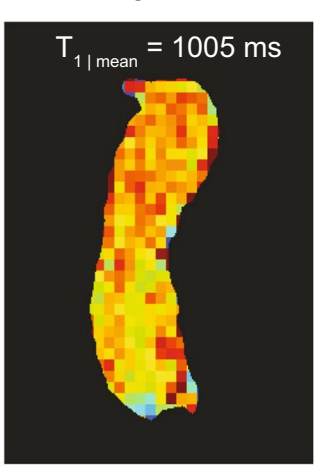

$21.1 \mathrm{~T}$

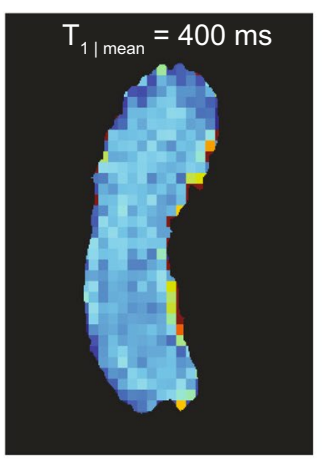

${ }^{19} \mathrm{~F} \mathrm{~T}_{1}$ maps
$\mathrm{T}_{1}(\mathrm{~ms})$

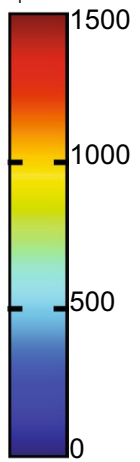

Fig. $6{ }^{19} \mathrm{~F}$ relaxation times for PFCE in ex vivo EAE spleen measured at 21.1 $\mathrm{T}$ and 9.4 T. Spleens were harvested from EAE mice that had been administered PFCE nanoparticles for 5 days during imitation of disease. a ${ }^{1} \mathrm{H}$ MR scan of the ex vivo EAE spleen positioned in an NMR tube using 3D-FLASH: TR=1500 ms, $\mathrm{TE}=6.5 \mathrm{~ms}, \quad \mathrm{FOV}=[20 \times 30 \times 3.6] \mathrm{mm}^{3}, \quad$ matrix $=400 \times 600 \times 72$,
$\mathrm{NA}=1, \mathrm{TA}=23 \mathrm{~m} . \mathbf{b} T_{1}$ maps were generated on one coronal slice of the spleen using RARE-VTR: $9 \times \mathrm{TRs}=50-12,000 \mathrm{~ms}, \mathrm{TE}=6.9 \mathrm{~ms}$, $\mathrm{ETL}=4, \mathrm{FOV}=[20 \times 30] \mathrm{mm}^{2}$, matrix $=44 \times 64$, slice thickness $=3.6 \mathrm{~mm}, \mathrm{NA}=128, \mathrm{TA}=15 \mathrm{~h} 50 \mathrm{~m}$. The averaged intensities over the coronal slice for all image series were fitted to the $T_{1}$ and $T_{2}$ equations
A

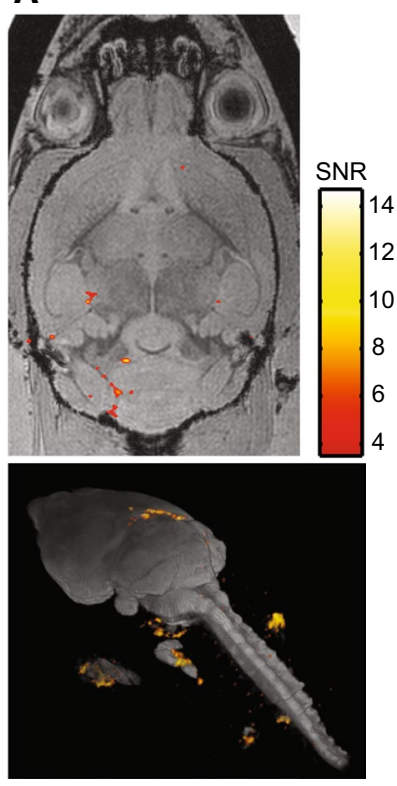

B
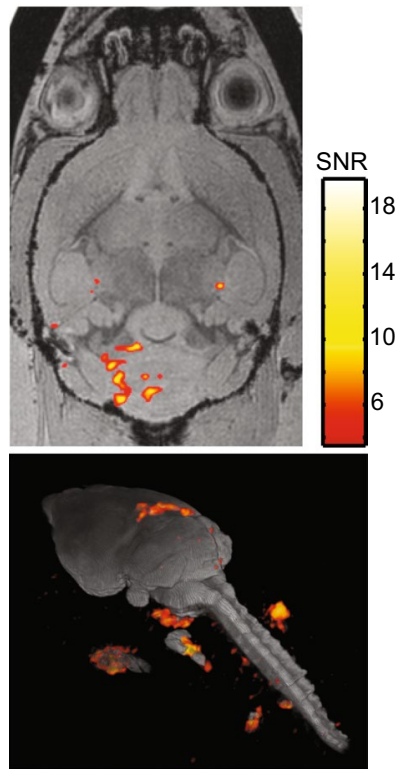

C
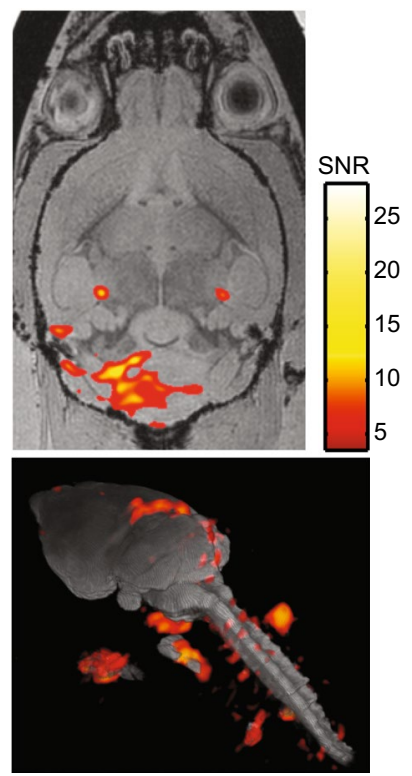

Fig. $7{ }^{19} \mathrm{~F}$ MR image of an ex vivo EAE mouse acquired at $21.1 \mathrm{~T}$ and at different spatial resolutions. ${ }^{19} \mathrm{~F}$ MR images were acquired using a 3D-RARE sequence acquired at three different spatial resolutions: a high: matrix $=195 \times 130 \times 130$, resolution $=153 \mu \mathrm{m}^{3}$, b medium: matrix $=135 \times 90 \times 90$, resolution $=222 \mu \mathrm{m}^{3}$, c low: matrix $=90 \times 60 \times 60$, resolution $=333 \mu \mathrm{m}^{3} .{ }^{19} \mathrm{~F}$ MR images $($ shown in red) were scaled to units of SNR (pseudocolor scale), thresholded at $\mathrm{SNR}=4$, and overlayed onto the FLASH ${ }^{1} \mathrm{H}$ anatomical MR images (shown in grayscale). For all three spatial resolutions both horizontal (upper panel) and 3D-render (lower panel) views of the EAE mouse brain and accompanying draining lymph nodes are shown are conceptually appealing due to the superiority of ${ }^{19} \mathrm{~F}$ nuclei over other MR-sensitive nuclei with regard to signal selectivity and specificity. However, they are constrained by sensitivity due to their typically low availability in vivo. Therefore, numerous efforts have been made to boost ${ }^{19} \mathrm{~F}$ signal, e.g., by optimizing the efficiency of the acquisition methods according to the $T_{1}$ and $T_{2}$ values of the specific ${ }^{19} \mathrm{~F}$ compounds [27], increasing the number of available ${ }^{19} \mathrm{~F}$ nuclei by promoting ${ }^{19} \mathrm{~F}$ nanoparticle cellular uptake [35] or by improving the sensitivity of the RF hardware by 
introducing cryogenically cooled RF probes [18]. Nevertheless, major challenges in signal sensitivity constraints remain. Improving ${ }^{19} \mathrm{~F}$ sensitivity using a combination of all currently available strategies, as well as developing new solutions, will be essential to realize the full potential of ${ }^{19} \mathrm{~F}$ MR.

Here, we studied the potential of increasing $\mathrm{B}_{0}$ for improving ${ }^{19} \mathrm{~F}$ MR signal sensitivity. Prior to the practical experiments, we estimated the expected SNR gain to be 2.7, when moving from 9.4 to $21.1 \mathrm{~T}$, taking into account the noise contributions for both MR systems and using the principle of reciprocity [15]. When we introduced the relationship of the reference power for both MR systems into Eq. (1), we estimated an SNR gain of $~ 3.8$. In our practical experiments, we realized an SNR gain of 2.1 when employing a 2D-RARE technique on different concentrations of nanoparticles. In 2D-FLASH measurements, the ratio in SNR efficiency (SNR $/ \sqrt{t}$ ratio) was estimated to be 7.29 , when comparing the best possible conditions (optimal TR and $\alpha$ ) at $21.1 \mathrm{~T}$ with those at $9.4 \mathrm{~T}$ and when including $T_{1}$ relaxation effects. Differences between the actual SNR gains determined experimentally and those expected from theory and simulations are conceivable, due to minor inaccuracies in the assumptions made for the EMF simulations. Factors such as sample noise, RF coil geometries, receive chain losses and preamplifier noise figure may add to the confounding influences that alter the actual SNR gain. In contrast to human imaging, the measurement noise in small animal imaging is dominated by the measurement hardware and not by the sample [36]. Thus in small animal MR scanners, differences in coil geometries and detector electronics can have a larger impact on the variations from expected sensitivity gains. Our estimations showed that in contrast to the 9.4 T RF coil, the intrinsic noise contribution of the 21.1 T RF coil was much lower than the sample noise contribution. However, the noise contributed by the relative long cables needed for the probe body $(\sim 2 \mathrm{~m})$ with the $21.1 \mathrm{~T}$ and preamplifier was estimated to be higher, indeed almost double those at the $9.4 \mathrm{~T}$ system. Therefore, the highest potential for increased SNR gains (potentially up to $40 \%$ ) at $21.1 \mathrm{~T}$ could be achieved by using the shortest cables possible (e.g., by placing the preamplifier as close to the coil as possible) or using preamplifiers with a lower noise figure.

Another factor that must be considered when investigating $\mathrm{B}_{0}$-influenced SNR changes is the potential changes in relaxation. Both spin-lattice $\left(T_{1}\right)$ and spin-spin $\left(T_{2}\right)$ relaxation times are expected to change with increasing $\mathrm{B}_{0}$ fields. The SNR gain of 3.8 derived from the simulations does not take changes in relaxation time into account. When $T_{1}$ relaxation effects were removed from the experimental data, we calculated an SNR/ $\sqrt{t}$ ratio of 5.25 (instead of 7). It is only in the fully relaxed regime that the SNR gain is expected to be influenced primarily by $\mathrm{B}_{0}$ and not influenced by $T_{1}$-weighting. Water shows a highly significant increase in $T_{1}$ relaxation and decrease in $T_{2}$ relaxation in different regions of the rat brain with increasing $B_{0}$ in the range from 4.0 to $11.7 \mathrm{~T}$ [31]. Knowledge of $T_{1}$ relaxation is particularly crucial for MR spectroscopy and quantification of specific compounds. Brain metabolites show a similar, but less pronounced trend as water with respect to proton relaxation. Conversely, macromolecules display a strong dependency of $T_{1}$ on $\mathrm{B}_{0}$, but $T_{2}$ is field independent [31]. Proton $T_{1}$ relaxation of brain metabolites does not increase substantially beyond $9.4 \mathrm{~T}$ (up to $14 \mathrm{~T}$ ) and any changes likely have minimal impact on sensitivity [37]. Particularly for ${ }^{19} \mathrm{~F}$ MR methods, where sensitivity is a crucial factor, it is critical to understand the mechanisms of $T_{1}$ relaxation. Interestingly, $T_{1}$ relaxation for ${ }^{19} \mathrm{~F}$ compounds appears to be inversely related to $\mathrm{B}_{0}$ strength. The decline in $T_{2}$ at higher $\mathrm{B}_{0}$ could hamper the expected increase in ${ }^{19} \mathrm{~F}$ MR signal at $21.1 \mathrm{~T}$ and warrants further consideration. The decline in $T_{1}$ with increasing $\mathrm{B}_{0}$ is consistent with previous studies [38, 39]. Thus far, a decrease in ${ }^{19} \mathrm{~F} T_{1}$ for ${ }^{19} \mathrm{~F}$ compounds has been attributed to an influence from dipole-dipole interactions and chemical shift anisotropy [38].

A decrease in $T_{1}$ for ${ }^{19} \mathrm{~F}$ compounds with increasing $\mathrm{B}_{0}$ has substantial ramifications, since this suggests the opportunity to increase SNR per unit time at higher magnetic field strengths by introducing more averaging. The $T_{1}$ shortening at $21.1 \mathrm{~T}$ observed in this study could provide one mechanism for the ratio in SNR efficiency (7.29) estimated from the 2D-FLASH experiments using optimal TRs and $\alpha$ specific to each $\mathrm{B}_{0}$ strength. The observations made here at $21.1 \mathrm{~T}$ are especially meaningful for studies that are hampered by the low availability of ${ }^{19} \mathrm{~F}$ spins and thus have a pressing need for sensitivity gains. An SNR gain could be exploited in several ways: e.g.. for a gain of 7.29, either the scan time could be reduced by a factor of 53 (e.g., from 60 to $\sim 1.1 \mathrm{~min}$ ) to obtain the original SNR or higher spatial resolution could be employed to achieve better image definition. In this study we made use of the SNR gain to acquire isotropic spatial resolutions of $150 \mu \mathrm{m}^{3}$ to study neuroinflammation ( ${ }^{19} \mathrm{~F}$ MR signals) more precisely. At this resolution, we aimed to gain more precise information regarding inflammatory cell localization in the brain, compared to our previous studies [6]. The level of detail achieved at $21.1 \mathrm{~T}$ was similar to that of the ${ }^{19} \mathrm{~F}$ MR images we recently obtained with a ${ }^{19} \mathrm{~F}$ cryogenic RF probe (CRP) where we reported on a maximal SNR gain of 15 and were able to study intraparenchymal inflammation at a high isotropic resolution of $150 \mu \mathrm{m}$ [18]. In the present study, we made the best feasible comparison of the sensitivity gains achievable between ${ }^{19} \mathrm{~F}$ CRP and a $\mathrm{B}_{0}$ increase to $21.1 \mathrm{~T}$, given the current hardware limitations. Although different RF coil sizes and geometries were used to make this comparison, we measured 
the same sample (pure PFCE) and used the same sequence parameters. Employing the 2D-FLASH technique used in the present study, we observed an SNR gain of 6.59 at 21.1 T when compared to 9.4 T, and an SNR gain of 7.49 with the CRP when compared to a room temperature coil of similar size. As discussed previously [18], the SNR gains achieved with the ${ }^{19} \mathrm{~F} \mathrm{CRP}$ can be attributed to several factors in addition to cooling: differences in RF coil design (birdcage vs. surface coil; quadrature versus linear), RF coil sample loading, and the specific RF pulse power adjustments all play important roles [18]. Even though the SNR gain achieved by moving from $9.4 \mathrm{~T}$ to $21.1 \mathrm{~T}$ is slightly lower than that realized at $9.4 \mathrm{~T}$ with a ${ }^{19} \mathrm{~F} \mathrm{CRP}$, the SNR gain at $21.1 \mathrm{~T}$ is consistent throughout the entire field of view due to the homogeneity of the RF volume coils used. This is in striking contrast to the CRP, which has an inherent limitation due to the declining gradient in the $\mathrm{B}_{1}$ field with increasing distance from the surface due to the transceive surface coil design [18]. Therefore in contrast to the ${ }^{19} \mathrm{~F} C R P,{ }^{19} \mathrm{~F}$ signals in ventral regions of the head were prominently detected with a resolution of $150 \mu \mathrm{m}$ at $21.1 \mathrm{~T}$. Given the difficulty of detecting ${ }^{19} \mathrm{~F}$ signals in these distal structures, most studies of the EAE model tend to focus exclusively on imaging of the brain. The advantages gained from using volume resonators at 21.1 $\mathrm{T}$ will allow a more comprehensive and detailed study of immune cell dynamics within the draining lymph nodes. On the other hand, studies focusing on the brain could be enhanced by using a CRP at this field strength. A fusion of both SNR boosting strategies has the potential for realizing even greater levels of detail when studying experimental brain pathologies.

Acknowledgements Part of this work was performed at the US National High Magnetic Field Laboratory (NHMFL), which is supported by the State of Florida and the National Science Foundation Cooperative Agreement No. DMR-1157490 and DMR-1644779. The study was funded by the Visiting Scientist Program of the NHMFL (227000-110, Project 12643 and by a research grant from the Deutsche Forschungsgemeinschaft to SW and AP (DFG WA2804, DFG PO1869). We thank Dr. Peter Schmieder, NMR expert at the LeibnizForschungsinstitut für Molekulare Pharmakologie (FMP), for helpful discussions on ${ }^{19} \mathrm{~F}$ relaxation.

Author contributions S. Waiczies: study conception and design, acquisition of data, analysis and interpretation of data, drafting of manuscript; J.T. Rosenberg: study conception and design, acquisition of data; A. Kuehne: analysis and interpretation of data, drafting of manuscript; L. Starke: analysis and interpretation of data; P. Ramos Delgado: analysis and interpretation of data, critical revision; J.M. Millward: drafting of manuscript, critical revision; C. Prinz: analysis and interpretation of data; J. dos Santos Periquito: analysis and interpretation of data; A. Pohlmann: analysis and interpretation of data, critical revision; $\mathrm{H}$. Waiczies: study conception and design, acquisition of data, analysis and interpretation of data; T. Niendorf: study conception and design, critical revision.
Funding The study was partly funded by the Visiting Scientist Program of the NHMFL (227000-110, Project 12643) and part of this work was performed at the US National High Magnetic Field Laboratory (NHMFL), which is supported by the State of Florida and the National Science Foundation Cooperative Agreement No. DMR-1157490 and DMR-1644779. This study was also partly funded by the Deutsche Forschungsgemeinschaft to S.W. (DFG WA2804) and A.P. (DFG PO1869). Thoralf Niendorf was funded (in part) by the European Research Council, ERC (ThermalMR, EU project 743077).

\section{Compliance with ethical standards}

Conflict of interest Thoralf Niendorf is founder and CEO of MRI. TOOLS GmbH, Berlin, Germany. All other authors declare no conflict of interest. Andre Kuehne and Helmar Waiczies are employees of MRI.TOOLS GmbH, Berlin, Germany.

Ethical approval All animal experiments were conducted in accordance with procedures approved by the Animal Welfare Department of the State Office of Health and Social Affairs Berlin (LAGeSo), and conformed to national and international guidelines to minimize discomfort to animals (86/609/EEC).

Open Access This article is distributed under the terms of the Creative Commons Attribution 4.0 International License (http://creativeco mmons.org/licenses/by/4.0/), which permits unrestricted use, distribution, and reproduction in any medium, provided you give appropriate credit to the original author(s) and the source, provide a link to the Creative Commons license, and indicate if changes were made.

\section{References}

1. Flögel U, Ding Z, Hardung H, Jander S, Reichmann G, Jacoby C, Schubert R, Schrader J (2008) In vivo monitoring of inflammation after cardiac and cerebral ischemia by fluorine magnetic resonance imaging. Circulation 118(2):140-148

2. Ahrens ET, Young WB, Xu H, Pusateri LK (2011) Rapid quantification of inflammation in tissue samples using perfluorocarbon emulsion and fluorine-19 nuclear magnetic resonance. Biotechniques 50(4):229-234

3. Flogel U, Burghoff S, van Lent PL, Temme S, Galbarz L, Ding Z, El-Tayeb A, Huels S, Bonner F, Borg N, Jacoby C, Muller CE, van den Berg WB, Schrader J (2012) Selective activation of adenosine A2A receptors on immune cells by a CD73-dependent prodrug suppresses joint inflammation in experimental rheumatoid arthritis. Sci Transl Med 4(146): 146 ra108

4. Temme S, Bonner F, Schrader J, Flogel U (2012) 19F magnetic resonance imaging of endogenous macrophages in inflammation. Wiley interdisciplinary reviews. Nanomed Nanobiotechnol 4(3):329-343

5. Ahrens ET, Zhong J (2013) In vivo MRI cell tracking using perfluorocarbon probes and fluorine-19 detection. NMR Biomed 26(7):860-871

6. Waiczies H, Lepore S, Drechsler S, Qadri F, Purfurst B, Sydow K, Dathe M, Kuhne A, Lindel T, Hoffmann W, Pohlmann A, Niendorf T, Waiczies S (2013) Visualizing brain inflammation with a shingled-leg radio-frequency head probe for $19 \mathrm{~F} / 1 \mathrm{H}$ MRI. Sci Rep 3:1280

7. Jacoby C, Temme S, Mayenfels F, Benoit N, Krafft MP, Schubert R, Schrader J, Flogel U (2014) Probing different perfluorocarbons for in vivo inflammation imaging by $19 \mathrm{~F} \mathrm{MRI:} \mathrm{image}$ 
reconstruction, biological half-lives and sensitivity. NMR Biomed 27(3):261-271

8. Grenier N, Merville P, Combe C (2016) Radiologic imaging of the renal parenchyma structure and function. Nat Rev Nephrol 12(6):348-359

9. Hueper K, Gutberlet M, Bräsen JH, Jang M-S, Thorenz A, Chen R, Hertel B, Barrmeyer A, Schmidbauer M, Meier M, von Vietinghoff S, Khalifa A, Hartung D, Haller H, Wacker F, Rong S, Gueler F (2016) Multiparametric functional MRI: non-invasive imaging of inflammation and edema formation after kidney transplantation in mice. PLoS One 11(9):e0162705

10. Ladd ME (2018) The quest for higher sensitivity in MRI through higher magnetic fields. Zeitschrift für Medizinische Physik 28(1):1-3

11. Niendorf T, Barth M, Kober F, Trattnig S (2016) From ultrahigh to extreme field magnetic resonance: where physics, biology and medicine meet. Magn Reson Mater Phys Biol Med 29(3):309-311

12. Hoult DI, Richards RE (1976) The signal-to-noise ratio of the nuclear magnetic resonance experiment. JMagn Reson (1969) 24(1):71-85

13. Hoult DI, Lauterbur PC (1979) Sensitivity of the zeugmatographic experiment involving human samples. J Magn Reson 34(2):425-433

14. Pohmann R, Speck O, Scheffler K (2016) Signal-to-noise ratio and MR tissue parameters in human brain imaging at 3, 7, and 9.4 tesla using current receive coil arrays. Magn Reson Med 75(2):801-809

15. Hoult DI (2000) The principle of reciprocity in signal strength calculations - a mathematical guide. Concepts Magn Reson 12(4):173-187

16. Guérin B, Villena JF, Polimeridis AG, Adalsteinsson E, Daniel L, White JK, Wald LL (2017) The ultimate signal-to-noise ratio in realistic body models. Magn Reson Med 78(5):1969-1980

17. Schepkin VD, Brey WW, Gor'kov PL, Grant SC (2010) Initial in vivo rodent sodium and proton MR imaging at 21.1 T. Magn Reson Imaging 28(3):400-407

18. Waiczies S, Millward JM, Starke L, Delgado PR, Huelnhagen T, Prinz C, Marek D, Wecker D, Wissmann R, Koch SP, BoehmSturm P, Waiczies H, Niendorf T, Pohlmann A (2017) Enhanced fluorine-19 MRI sensitivity using a cryogenic radiofrequency probe: technical developments and ex vivo demonstration in a mouse model of neuroinflammation. Sci Rep 7(1):9808

19. Fu R, Brey WW, Shetty K, Gorkov P, Saha S, Long JR, Grant SC, Chekmenev EY, Hu J, Gan Z, Sharma M, Zhang F, Logan TM, Brüschweller R, Edison A, Blue A, Dixon IR, Markiewicz WD, Cross TA (2005) Ultra-wide bore $900 \mathrm{MHz}$ high-resolution NMR at the national high magnetic field laboratory. J Magn Reson 177(1): $1-8$

20. Abad N, Rosenberg JT, Roussel T, Grice DC, Harrington MG, Grant SC (2018) Metabolic assessment of a migraine model using relaxation-enhanced $1 \mathrm{H}$ spectroscopy at ultrahigh field. Magn Reson Med 79(3):1266-1275

21. Ananda K, Edelstein WA, Bottomley PA (2009) Noise figure limits for circular loop MR coils. Magnetic Resonance in Medicine 61(5):1201-1209

22. Waiczies H, Lepore S, Janitzek N, Hagen U, Seifert F, Ittermann B, Purfurst B, Pezzutto A, Paul F, Niendorf T, Waiczies S (2011) Perfluorocarbon particle size influences magnetic resonance signal and immunological properties of dendritic cells. PLoS One 6(7):e21981
23. NEMA (2008) Determination of signal-to-noise ratio (SNR) in diagnostic magnetic resonance imaging. National Electrical Manufacturers Association Standards Publication MS:1-2008

24. Henkelman RM (1985) Measurement of signal intensities in the presence of noise in MR images. Med Phys 12(2):232-233

25. Gudbjartsson H, Patz S (1995) The Rician Distribution of Noisy MRI Data. Magn Reson Med 34(6):910-914

26. Constantinides CD, Atalar E, McVeigh ER (1997) Signal-to-noise measurements in magnitude images from NMR phased arrays. Magn Reson Med 38(5):852-857

27. Faber C, Schmid F (2016) Chapter 1 pulse sequence considerations and schemes. In: Fluorine magnetic resonance imaging. Pan Stanford Publishing, pp 1-28

28. Haacke EM (1999) Magnetic resonance imaging physical principles and sequence design, vol xxvii. Wiley, Hoboken, p 914

29. Ernst RR, Anderson WA (1966) Application of Fourier transform spectroscopy to magnetic resonance. Rev Sci Instrum 37(1):93-102

30. Yushkevich PA, Piven J, Hazlett HC, Smith RG, Ho S, Gee JC, Gerig G (2006) User-guided 3D active contour segmentation of anatomical structures: Significantly improved efficiency and reliability. NeuroImage 31(3):1116-1128

31. de Graaf RA, Brown PB, McIntyre S, Nixon TW, Behar KL, Rothman DL (2006) High magnetic field water and metabolite proton $T_{1}$ and $T_{2}$ relaxation in rat brain in vivo. Magn Reson Med 56(2):386-394

32. Rooney WD, Johnson G, Li X, Cohen ER, Kim S-G, Ugurbil K, Springer CS (2007) Magnetic field and tissue dependencies of human brain longitudinal $1 \mathrm{H} 2 \mathrm{O}$ relaxation in vivo. Magn Reson Med 57(2):308-318

33. Nöth U, Morrissey SP, Deichmann R, Jung S, Adolf H, Haase A, Lutz J (1997) Perfluoro-15-crown-5-ether labelled macrophages in adoptive transfer experimental allergic encephalomyelitis. Artif Cells Blood Substitutes Biotechnol 25(3):243-254

34. Zhong J, Narsinh K, Morel PA, Xu H, Ahrens ET (2015) In vivo quantification of inflammation in experimental autoimmune encephalomyelitis rats using fluorine-19 magnetic resonance imaging reveals immune cell recruitment outside the nervous system. PLoS ONE 10(10):e0140238

35. Waiczies S, Lepore S, Sydow K, Drechsler S, Ku MC, Martin C, Lorenz D, Schutz I, Reimann HM, Purfurst B, Dieringer MA, Waiczies H, Dathe M, Pohlmann A, Niendorf T (2015) Anchoring dipalmitoyl phosphoethanolamine to nanoparticles boosts cellular uptake and fluorine-19 magnetic resonance signal. Sci Rep 5:8427

36. Niendorf T, Pohlmann A, Reimann HM, Waiczies H, Peper E, Huelnhagen T, Seeliger E, Schreiber A, Kettritz R, Strobel K, Ku MC, Waiczies S (2015) Advancing cardiovascular, neurovascular, and renal magnetic resonance imaging in small rodents using cryogenic radiofrequency coil technology. Front Pharmacol 6:255

37. Cristina C, Vladimír M, Lijing X, Rolf G (2009) Comparison of $T_{1}$ relaxation times of the neurochemical profile in rat brain at 9.4 and 14.1 tesla. Magn Reson Med 62(4):862-867

38. Kadayakkara DK, Damodaran K, Hitchens TK, Bulte JW, Ahrens ET (2014) 19)F spin-lattice relaxation of perfluoropolyethers: dependence on temperature and magnetic field strength (7.0-14.1 T. J Magn Reson 242:18-22

39. Duong TQ, Iadecola C, Kim S-G (2001) Effect of hyperoxia, hypercapnia, and hypoxia on cerebral interstitial oxygen tension and cerebral blood flow. Magn Reson Med 45(1):61-70 